\title{
RESPIRATORY FAILURE AND CARBON DIOXIDE NARCOSIS
}

\author{
By E. Keith Westlake, M.A., M.D., M.R.C.P.
} Senior Medical Registrar, Middlesex Hospital

All physicians are familiar with the clinical and biochemical manifestations of cardiac and renal failure, but the syndrome of respiratory failure has gained recognition more slowly. The primary function of the lungs is to maintain a constant exchange of oxygen and carbon dioxide between the blood and air. This is achieved by intermittent flushing of the alveoli with inspired air and the continuous diffusion of oxygen and carbon dioxide across the alveolar membrane. In normal individuals, these processes maintain the mean carbon dioxide tension $\left(\mathrm{pCO}_{2}\right)$ in the alveoli at $40 \pm 5$ $\mathrm{mm}$. $\mathrm{Hg}$. and the oxygen tension $\left(\mathrm{pO}_{2}\right)$ at $100 \pm 5$ $\mathrm{mm}$. Hg. Respiratory failure may be said to be present when there is inability or failure of the repiratory centre and neuro-muscular mechanism to prevent the alveolar $\mathrm{pCO}_{2}$ rising above, and the alveolar $\mathrm{pO}_{2}$ falling below their normal values. The level of alveolar $\mathrm{pCO}_{2}$ is determined by two variables: (a) the rate of carbon dioxide production by the body i.e. the metabolic rate and (b) the adequacy of alveolar ventilation. If the metabolic rate remains constant, the alveolar $\mathrm{pCO}_{2}$ will vary inversely with alveolar ventilation. If the latter is halved, the $\mathrm{pCO}_{2}$ will rise to double its original level and vice-versa. Similarly, if the rate of carbon dioxide production is doubled, alveolar ventilation must increase to the same extent if the alveolar $\mathrm{pCO}_{2}$ is to remain unchanged. Respiratory failure is therefore characterized by relative underventilation of the lung alveoli in relation to body metabolism.

When breathing air, alveolar hypoventilation inevitably causes hypoxaemia (arterial oxygen unsaturation) as well as hypercapnia (raised arterial $\mathrm{pCO}_{2}$ ) since as the level of alveolar $\mathrm{pCO}_{2}$ rises, the alveolar $\mathrm{pO}_{2}$ falls. The relationship between the alveolar gas tensions can be appreciated from the equation derived by Fenn, Rahn and Otis (1946)* and depends on the respiratory quotient (R.Q.)

\footnotetext{
* Mean alveolar $\mathrm{pO}_{2}=(\mathrm{B}-47) \times 0.21$ - alveolar $\mathrm{pCO}_{2}\left(0.2 \mathrm{I}+\frac{0.79}{\text { R.Q. }}\right)$.
}

and the prevailing barometric pressure (B). For example, when the respiratory quotient is 0.79 and $\overparen{Q}$ the barometric pressure $760 \mathrm{~mm}$., this equation simplifies to: $\mathrm{pO}_{2}=150-\mathrm{I} .2 \mathrm{I} \times$ alveolar $\mathrm{pCO}_{2}$. Thus at the normal alveolar $\mathrm{pCO}_{2}$ of $40 \mathrm{~mm}$., the corresponding $\mathrm{pO}_{2}$ will be $102 \mathrm{~mm}$., but if the alveolar $\mathrm{pCO}_{2}$ rises to $80 \mathrm{~mm}$., the alveolar $\mathrm{pO}_{2}$ i must fall to $53 \mathrm{~mm}$. (150-1.21 $\times 80)$. Capillary 을 blood leaving the alveoli cannot have an oxygen tension higher than this figure and the oxygen saturation of arterial blood will therefore be reduced to about 80 per cent. with the appearance of central cyanosis.

When the alveolar $\mathrm{pCO}_{2}$ is suddenly raised frop 40 to $80 \mathrm{~mm}$., the volume of carbon dioxide dis solved in the arterial plasma increases from 2.9 vols. per $100 \mathrm{ml}$. to 5.6 vols. with consequent fall in blood $\mathrm{pH}$ from 7.4 to 7.I. Renal compensation for this respiratory acidaemia, with partial restoration of the arterial $\mathrm{pH}$ toward normal, is brought about over a period of days by increased tubular reabsorption of bicarbonate and the excretion of a

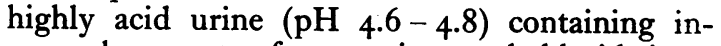
creased amounts of ammonium and chloride ions. Thus the biochemical effect of respiratory failure is the combination of hypercapnia, hypoxaemia and acidaemia.

\section{Causes of Respiratory Failure}

Respiratory failure may result from organic disease of the central nervous system (for example, encephalitis lethargica (Barach and Woodwell, I92I), bulbo-spinal poliomyelitis (Plum and Wolff, 195I), motor neurone disease (Feltman o et al., 1952), brain stem haemorrhage) or of the respiratory muscles (for example, dystrophia myotonica (Benaim and Worster-Drought, I954), myasthenia gravis, dermatomyositis). In general medicine, respiratory failure is most commonly encountered in patients with long standing chest disease whose ventilatory capacity is grossly diminished e.g. in chronic bronchitis and emphysema (Baldwin et al., 1949) and severe kyphoscoliosis (Fishman et al., 1956). Patients who are 


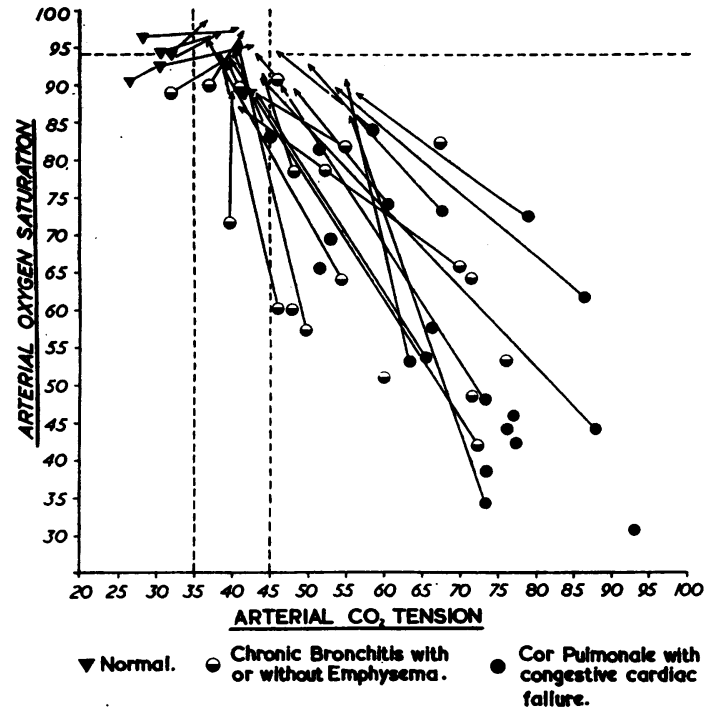

FIG. I.-Respiratory failure precipitated by an acute chest infection in patients with chronic lung disease. Arterial oxygen saturation and carbon dioxide tension on admission with, and recovery from, an acute respiratory infection. Single points represent patients who died.

able to maintain a normal alveolar $\mathrm{pCO}_{2}$ when well, frequently develop acute respiratory failure with severe hypoxaemia and hypercapnia when subjected to the stress of a respiratory infection (Westlake, 1954). This is illustrated in Fig. I. In this diagram the arterial oxygen saturation and $\mathrm{pCO}_{2}$ during the course of an acute respiratory infection have been plotted as oblique arrows. The six normal subjects i.e. those without previous respiratory symptoms (represented by black triangles) were all suffering from extensive lobar pneumonia and in five the $\mathrm{pCO}_{2}$ on admission to hospital was lower than that on recovery. This may be taken as the normal response to an acute chest infection. In the 39 patients with a previous history of chest disease (chronic bronchitis, emphysema and cor pulmonale), the arterial $\mathrm{pCO}_{2}$ on admission was higher than on recovery in 37 . In many instances the initial levels of $\mathrm{pCO}_{2}$ were 30 to $40 \mathrm{~mm}$. higher than those on recovery. Other factors that may precipitate respiratory failure in patients with chronic chest disease are severe asthma (Schiller et al., 195I; Sieker and Hickam, 1956), chest surgery (Björk and Engström, 1955) and the ill-advised administration of morphine and other drugs which depress the sensitivity of the respiratory centre (Roussak, 1951; Samuelsson, 1952; Wilson, Hoseth and Dempsey, 1954). In rare instances, chronic respiratory failure occurs in the absence of either pulmonary or neurological disease, usually in association with gross obesity (Burwell et al., I956).

\section{The Diagnosis of Respiratory Failure}

Clinical recognition of alveolar hypoventilation may be difficult and the only certain method of diagnosis is the demonstration of a raised level of $\mathrm{pCO}_{2}$. This is most conveniently achieved by analysis of arterial blood since the $\mathrm{pCO}_{2}$ of alveolar air and arterial blood are virtually identical. With practice, samples of arterial blood can be readily obtained by puncture of the brachial artery under local analgesia. Direct determination of both $\mathrm{pCO}_{2}$ and $\mathrm{pO}_{2}$ in arterial blood can be made by the bubble equilibration technique devised by Riley. This method has been extensively used in respiratory research but is technically too difficult for routine use in a biochemical laboratory. However, arterial $\mathrm{pCO}_{2}$ can be accurately estimated by an indirect method. Blood $\mathrm{pH}, \mathrm{pCO}_{2}$ and total plasma $\mathrm{CO}_{2}$ content are related by the wellknown Henderson-Hasselbalch equation. If any two of these variables are known, then the third can be calculated. Thus, rearranging the equation: Total plasma $\mathrm{CO}_{2}$ content $\mathrm{mM} / \mathrm{L}$

$$
\mathrm{pCO}_{2}=\frac{\mathrm{T}}{0.03 \times(\text { antilog blood } \mathrm{pH}-6.09)+\mathrm{I}}
$$

Total plasma $\mathrm{CO}_{2}$ content is measured by the manometric method of Van Slyke and Neill (1924) and blood $\mathrm{pH}$ with a glass electrode and $\mathrm{pH}$ meter. Practical details for measuring blood $\mathrm{pH}$ at body temperature are to be found in the papers of Wilson (195I), Severinghaus, Stupfel and Bradley (1956) and Wynn and Ludbrook (1957).

\section{The Clinical Manifestations of Respiratory Failure}

The disturbances of blood gas tensions and in blood $\mathrm{pH}$ caused by respiratory failure have profound physiological effects on the brain, cerebral vessels, heart and lungs and are responsible for the appearance of certain characteristic signs and symptoms which may make a bed-side diagnosis of respiratory failure possible.

Mental disturbance in respiratory failure varies with its severity. In mild cases the patient may be euphoric or mildly confused. More severe degrees of hypoxaemia and hypercapnia cause progressive deterioration in mental function with visual and auditory hallucinations, delusions, stupor and finally coma. Although disturbed mental function is principally due to cerebral anoxia (Simpson, 1957), the effects of hypercapnia and acidaemia on the brain should not be neglected. The effect of breathing 100 per cent. oxygen shows that hypoxaemia is only one of the factors concerned since the patient in respiratory failure, although considerably improved, often 
remains confused and disorientated despite full saturation of the arterial blood with oxygen. If mental disturbance were solely due to hypoxaemia, an immediate return to mental clarity would be expected. Impaired memory is usual during a period of respiratory failure, even in the absence of obvious mental disturbance. After recovery from an acute respiratory infection, careful enquiry will often reveal that the patient has complete amnesia (lasting days or even a week or two) for the early phase of his illness, although at the time, he may have appeared alert and rational. Muscular twitching is another common neurological manifestation of respiratory failure. It consists of coarse, irregular, jerky movements of the fingers, arms and facial muscles and, less frequently of the trunk and legs. Similar movements have been observed in normal subjects exposed to severe anoxia.

A low arterial $\mathrm{pO}_{2}$, high $\mathrm{pCO}_{2}$ and low $\mathrm{pH}$ all cause dilatation of the cerebral and retinal vessels, the volume of blood within the skull is increased and in consequence the C.S.F. pressure rises. In 12 emphysematous patients studied during respiratory infections (Westlake and Kaye, I954), the C.S.F. pressure was above the upper limit of normal ( $200 \mathrm{~mm}$.) in ten, and in five subjects it was over $350 \mathrm{~mm}$. The highest pressure recorded was $600 \mathrm{~mm}$. Raised intracranial pressure due to respiratory failure is frequently associated with a severe throbbing type of headache and in a few patients, frank papilloedema appears, with measurable swelling of the nerve head, gross dilatation of the retinal veins and flame-shaped haemorrhages. Papilloedema as a complication of emphysema was first described by Cameron (I933), and although some authors have attributed the phenomenon to raised venous pressure (Beaumont and Hearn, 1948), the work of Simpson (1948) leaves no doubt that the primary cause is cerebral vasodilatation consequent to respiratory failure, although in some cases raised jugular venous pressure may be a contributory factor. The combination of mental disturbance, headache and papilloedema may lead to an erroneous diagnosis of cerebral tumour as in the cases reported by Meadows (1947) and Conn et al. (1957).

While respiratory failure causes cerebral vasodilatation, it has the opposite effect on the pulmonary arterioles and the pulmonary artery pressure rises (Whitaker, 1954). In patients with pre-existing hypertrophy of the right ventricle (cor pulmonale) the sudden increase in pulmonary artery pressure that occurs during acute respiratory infections frequently precipitates heart failure with dilatation of the right ventricle, the appearance of gallop rhythm (best heard over the xiphisternum), raised venous pressure and peripheral oedema
(Stone et al., 1953; Fulton, 1953; Flint, 1954). The cardiac output is usually normal or even $\frac{2}{3}$ moderately raised (Ferrer et al., 1950; Mounsey $\frac{a}{2}$ et al., 1952) and this, together with the vasodilator $c$. effect of hypoxaemia and hypercapnia on the small $\overrightarrow{\overrightarrow{\vec{F}}}$ vessels of the limbs, is responsible for the warm $\stackrel{\vec{P}}{+}$ extremities and bounding pulse present during episodes of congestive failure-in contrast to con- 흠 gestive failure in mitral stenosis, hypertension or $\frac{\bar{\sigma}}{\sigma}$ ischaemic heart disease where the cardiac output $\stackrel{\circledast}{\varrho}$ is low and the extremities cold. As might be expected, congestive failure is most likely to occur $\vec{\circ}$ when respiratory failure is severe. From Fig. I, it can be seen that of I I patients with an arterial $\vec{\omega}$ oxygen saturation below 55 per cent. and $\mathrm{pCO}_{2} \stackrel{\text { }}{\circ}$ above $70 \mathrm{~mm}$., signs of heart failure were absento in only three.

Many of the features of respiratory failure are $\underset{+}{\dot{\omega}}$ illustrated by the following case history: A 63year-old log sawyer was admitted to hospital on January 12, 1955. Apart from a chronic 'smoker's' 0 cough with scanty mucoid sputum he had been in $\frac{}{3}$ good health until 1943, when he had a severe $\vec{c}$ attack of acute bronchitis. Since then he had been subject to repeated exacerbations of winter bronchitis with purulent sputum, headache and wheeziness. In $195 \mathrm{I}$, he noticed moderate exer $\vec{c}$ tional dyspnoea but this was not severe enough interfere with his work. On January 3, 1955. after walking home in a gale, he felt ill and retire to bed. Subsequently his sputum became purulent and he complained of anorexia, wheeziness, insomina and severe throbbing headaches. On January 7,1955 , his practitioner prescribed $a \stackrel{\mathbb{Q}}{2}$ four-day course of aureomycin ( $0.25 \mathrm{~g}$. six-hourly) $\overrightarrow{\overrightarrow{0}}$ but despite this he continued to deteriorate, and on 3 January 9, 1955, was disorientated with rambling speech and hallucinations. On admission three days later he appeared critically ill. There was deep cyanosis of the lips and nail beds, the neck veins were engorged to the angle of the jaw and he was unable to give any coherent history. Examination of the fundi showed dilated, tortuous veins with some blurring of the disc margins but no retinal haemorrhages. Heart sounds were normal $\frac{9}{2}$ with a regular tachycardia, rate Ioo. Blood $\frac{D}{2}$ pressure I I 5/55. Mild sacral oedema was present. Respirations were shallow and rapid and on $N$ auscultation of the chest coarse rales were audible at both bases with generalized inspiratory and $\mathcal{N}$ expiratory rhonchi. The resting ventilation was $\mathrm{\omega}$ 6.25 litres per minute (respiratory rate $40 \times$ tidal 2 air $156 \mathrm{ml}$.). Analysis of arterial blood confirmed the clinical diagnosis of severe respiratory failure: oxygen saturation 44 per cent. ( $\mathrm{pO}_{2} 26 \mathrm{~mm}$.), $\stackrel{?}{+}$ $\mathrm{pCO}_{2}$ raised to $88 \mathrm{~mm}$. (more than twice normal) and $\mathrm{pH}$ reduced to 7.24 (normal range $7.36-7.44$ ). $\frac{\mathrm{P}}{\mathrm{D}}$ A chest radiograph showed considerable cardiac 
CARBON DIOXIDE NARCOSIS

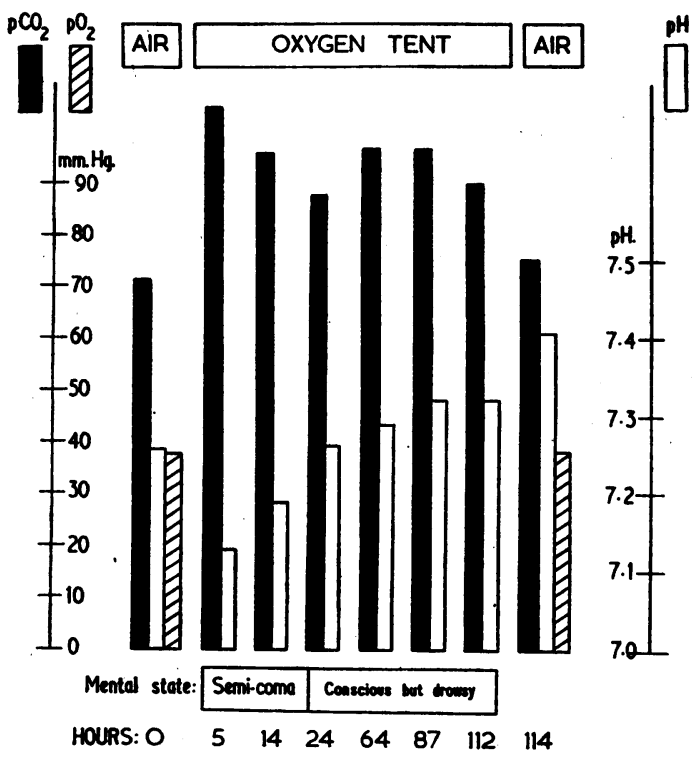

FIG. 2.-Development of carbon dioxide narcosis during oxygen therapy.

enlargement but the lung fields were clear. Treatment with oxygen, antibiotics, bronchodilators, nikethamide and corticotrophin resulted in rapid recovery from respiratory failure and disappearance of the signs of right heart failure. Studies on recovery showed that the arterial blood was still mildly unsaturated $\left(\mathrm{O}_{2}\right.$ saturation 91.4 per cent.), but that the $\mathrm{pCO}_{2}(44 \mathrm{~mm}$.) and $\mathrm{pH}(7.42)$ had returned to normal. The resting ventilation was again 6.2 litres per minute but the larger tidal air (310 ml.) now provided adequate alveolar ventilation. He subsequently returned to work and has remained in good health.

\section{Carbon Dioxide Narcosis}

In respiratory failure, there is a shift in the control of pulmonary ventilation from the medullary respiratory centre to the peripheral chemoreceptors of the carotid and aortic bodies. With rising arterial $\mathrm{pCO}_{2}$, the respiratory centre becomes less and less sensitive to the stimulus of carbon dioxide (Scott, 1920; Tenney, 1954; Prime and Westlake, 1954; Fishman et al., 1955) and ventilation is increasingly maintained by the stimulus of hypoxaemia acting via the carotid and aortic chemoreceptors. Breathing high concentrations of oxygen abolishes the anoxic stimulus to breathing with the inevitable consequence that alveolar and arterial $\mathrm{pCO}_{2}$ levels are raised and arterial $\mathrm{pH}$ lowered still further. It is this phenomenon that is responsible for the development of carbon dioxide narcosis during oxygen therapy (Barach, 1935; Donald, 1949; Comroe, Bahnson and Coates, I950; Cohn, Carroll and Riley, 1954; Westlake, Simpson and Kaye, r955; Sieker and Hickam, 1956). A typical example is illustrated in Fig. 2. The patient, a 62-year-old emphysematous man developed an acute pneumococcal bronchitis with moderately severe respiratory failure: oxygen saturation 64 per cent. $\left(\mathrm{pO}_{2} 38 \mathrm{~mm}\right.$.), $\mathrm{pCO}_{2} 72 \mathrm{~mm}$. and $\mathrm{pH}$. 7.26. On admission to hospital he was rational and orientated but within four hours of being placed in an oxygen tent he had lapsed into a semicomatose state with profuse sweating and coarse myoclonic jerking of the arms. Arterial blood showed that the $\mathrm{pCO}_{2}$ had risen to $105 \mathrm{~mm}$. with fall in $\mathrm{pH}$ to 7.13 (equivalent to the inhalation of 15 per cent. carbon dioxide by a normal subject). Over succeeding days, the arterial $\mathrm{pH}$ gradually returned toward normal values and the arterial $\mathrm{pCO}_{2}$ fell to $90 \mathrm{~mm}$. Myoclonic jerking ceased and the patient regained consciousness but remained unduly drowsy. Throughout the period of oxygen therapy, the arterial blood remained fully saturated with oxygen.

A broad correlation has been established between arterial $\mathrm{pCO}_{2}, \mathrm{pH}$ and mental state. Westlake, Simpson and Kaye (1955) found that mental disturbance was usually present when the arterial $\mathrm{pH}$ was less than 7.2 or the $\mathrm{pCO}_{2}$ above roo $\mathrm{mm}$., and coma when the $\mathrm{pH}$ fell below 7.1 or the $\mathrm{pCO}_{2}$ rose above $120 \mathrm{~mm}$. Most patients were conscious and rational if the $\mathrm{pH}$ was above 7.3 or $\mathrm{pCO}_{2}$ less than $80 \mathrm{~mm}$. These observations have been substantially confirmed by Sieker and Hickam (1956). They observed that there was usually no significant abnormality in mental state if the $\mathrm{pCO}_{2}$ was less than $90 \mathrm{~mm}$. and the $\mathrm{pH}$ above 7.25. Semi-coma or coma were always observed when the $\mathrm{pCO}_{2}$ rose above $130 \mathrm{~mm}$. and $\mathrm{pH}$ fell below 7.14. In general, the critical level for loss of consciousness in carbon dioxide intoxication is at a $\mathrm{pH}$ of 7.1-7.14 and $\mathrm{pCO}_{2}$ of $120-130 \mathrm{~mm}$., although increased susceptibility to the narcotic action of carbon dioxide may be found in individual cases.

Motor phenomena are common during carbon dioxide intoxication. They usually consist of fine tremors of the fingers, arms and facial muscles (Waters, 1937), but severe clonic movements of the limbs and generalized convulsions have been observed (Sieker and Hickam, 1956). The C.S.F. pressure often rises (Davies and Mackinnon, I949; Westlake and Kaye, 1954)-despite relief of anoxic cerebral vasodilatation-and papilloedema may make its first appearance during oxygen therapy. Carbon dioxide intoxication also causes tachycardia, sweating, skin vasodilatation and alterations in blood pressure. In the early stage the blood 
pressure may rise, but more severe degrees of hypercapnia and acidaemia are usually associated with a profound fall in blood pressure. Prolonged narcosis frequently causes death from respiratory depression.

\section{BIBLIOGRAPHY}

BALDWIN, E. DE F., COURNAND, A., and RICHARDS, D. W. (1949), Medicine, 28, I.

BARACH, A. L. (1935), Anesth. et Analg., 14, 79.

BARACH, A. L., and WOODWELL, M. N. (1921), Arch. int. Med., 28, 421 .

BEAUMONT, G. E., and HEARN, J. B. (1948), Brit. med. f., i, 50. BENAIM, S., and WORSTER-DROUGHT, C. (r954), Med. ill. (Lond.), 8, 221.

BJÖRK, V. O., and ENGSTROMM, C. G. (1955), f. thorac. Surg., 30, 356 .

BURWELL, C. S., ROBIN, E. D., WHALEY, R. D., and BICKELMANN, A. G. (1956), Amer. $\mathcal{F}$. Med., 21, 8 I I.

CAMERON, A. J. (1933), Brit. $\mathcal{~}$. Ophthal., 17, 167.

COHN, J. E., CARROLL, D. G., and RILEY, R. L. (1954), Amer. F. Med., 17, 447.

CONN, H. O., DUNN, J. P., NEWMAN, H. A., and BELKIN, G. A. (1957), Ibid., 22, 524 .

COMROE, J. H., BAHNSON, E. R., and COATES, E. O. (1950), F. Amer. med. Ass., 143, 1044.

DAVIES, C. E., and MACKINNON, J. (1949), Lancet, ii, $88_{3}$.

DONALD, K. W. (1949), Ibid., ii, ro56.

FELTMAN, J. A., NEWMAN, W., SCHWARTZ, A., STONE, D. J., and LOVELOCK, F. J. (I952), 7 . clin. Invest., 31, 762.

FENN, W. O., RAHN, H., and OTIS, A. B. (1946), Amer. F. Physiol., 146, 637.

FERRER, M. I., HARVEY, R. M., CATHCART, R. T., WEBSTER, Ċ. A., RICHARDS, D.' W., and COURNÁND, A. (1950), Circulation, I, I6r.
FISHMAN, A. P., BERGOFSKY, E. H., TURINO, G. H. JAMESON, A.' G., and RICHARDS, D. W. (1956), Ibid., 14, 935 .

FISHMAN, A. P., SAMET, P., and COURNAND, A. (1955), Amer. Э. Med., 19, 533.

FLINT, F. J. (1954), Lancet, ii, 5 I.

FULTON, R. M. (1953), Quart. F. Med., 22, 43.

MEADOWS, S. P. (1947), Proc. roy. Soc. Med., 40, 555.

MOUNSEY, J. P. D., RITZMANN, L. W., SELVERSTONE N. J., BRISCOE, W. A., and MCLEMORE, G. A. (1952), Brit. Heart F., 14, I 53.

PLUM, F., and WOLFF, H. G. (1951), f. Amer. med. Ass., 146, 472. PRIME, F. J., and WESTLAKE, E. K. (r954), Clin. Sci., 13, 321 . ROUSSAK, N. J. (195I), Lancet, i, 1156.

SAMUELSSON, S. (1952), Cardiologica, 21, 817.

SCHILLER, I. W., BEALE, H. D., FRANKLIN, W., LOWELL, F. C., and HÁLPERIN, M. H. (1951), $\mathcal{F}$. Allergy, 22, 423. SCOTT, R. W. (1920), Arch. int. Med., 26, 544.

SEVERINGHAUS, J. W., STUPFEL, M., and BRADLEY, A. F. (1956), F. aptl. Physiol., 9, 189.

SIEKER, H. O., and HICKAM, J. B. (1956), Medicine, 35, 389.

SIMPSON, T. (1948), Brit. med. F., ii, 639.

SIMPSON, T. (1957), Lancet, ii, 105.

STONE, D. J., SCHWARTZ, A., NEWMAN, W., FELTMAX, J. A., and LOVELOCK, F. J.'(I953), Amer. F. Med., 14, 14.

TENNEY, S. M. (1954), f. appl. Physiol., 6, 477.

WATERS, R. M. (1937), New Orleans med. surg. F., 90, 2 1 9.

WESTLAKE, E. K. (1954), Brit. med. $\mathcal{F}$., ii, 1012.

WESTLAKE, E. K., and KAYE, M. (1954), 1, 302.

WESTLAKE, E. K., SIMPSON, T., and KAYE, M. (1955), Quart. F. Med., 2, 155.

WHITAKER, W. (1954), Ibid., 23, 57.

WILSON, R. H. (195I), F. Lab. clin. Med., 37, I 29.

WILSON, R. H., HOSETH, W., and DEMPSEY, M. E. (I954), Amer. F. Med., 17, 464 .

IVYNN, V., and LUDBROOK, J. (1957), Lancet, i, 1068.

VAN SLYKE, D. D., and NEILL, J. M. (1924), f. biol. Chem., 61,523 .
Lucozade requires no preparation. It is a lightly carbonated glucose solution with an attractive golden colour and a pleasant citrous flavour. The liquid glucose content is $23.5 \% \mathrm{w} / \mathrm{v}$ or about 2 I calories for each fluid ounce. 